\title{
If it's not one thing, it's another
}

Some physical discomforts are common during pregnancy. You will want to know how to ease discomforts like nausea and vomiting, heartburn, constipation, leg cramps and backaches. Here are some remedies that really work:

\section{For nausea and vomiting:}

- Eat small, high-carbohydrate, low-fat meals and snacks like pasta, rice and toast every two to three hours.

- Eat whole-wheat crackers, pretzels or cereal before getting out of bed in the morning.

- Eat fruit ices, popsicles, sherbet and lemon drops.

- Avoid long periods without eating since an empty stomach may increase nausea.

- Separate the intake of liquids and solids by about one hour.

- Avoid greasy, fried and high-fat foods.

- Highly seasoned or spicy foods may trigger nausea or vomiting. Avoid any foods that bother you.

- Avoid strong odors like cooking smells, cigarette smoke and perfume.

- Get plenty of fresh air and moderateintensity physical activity like walking.

- Avoid brushing your teeth early in the morning - it may cause a gag reflex.

- Avoid cigarette smoking, alcohol and caffeine.

- Drink caffeine-free carbonated beverages or lemonade.

- Chew peppermint gum.

- Get plenty of sleep and rest - lie down when you feel nauseated.
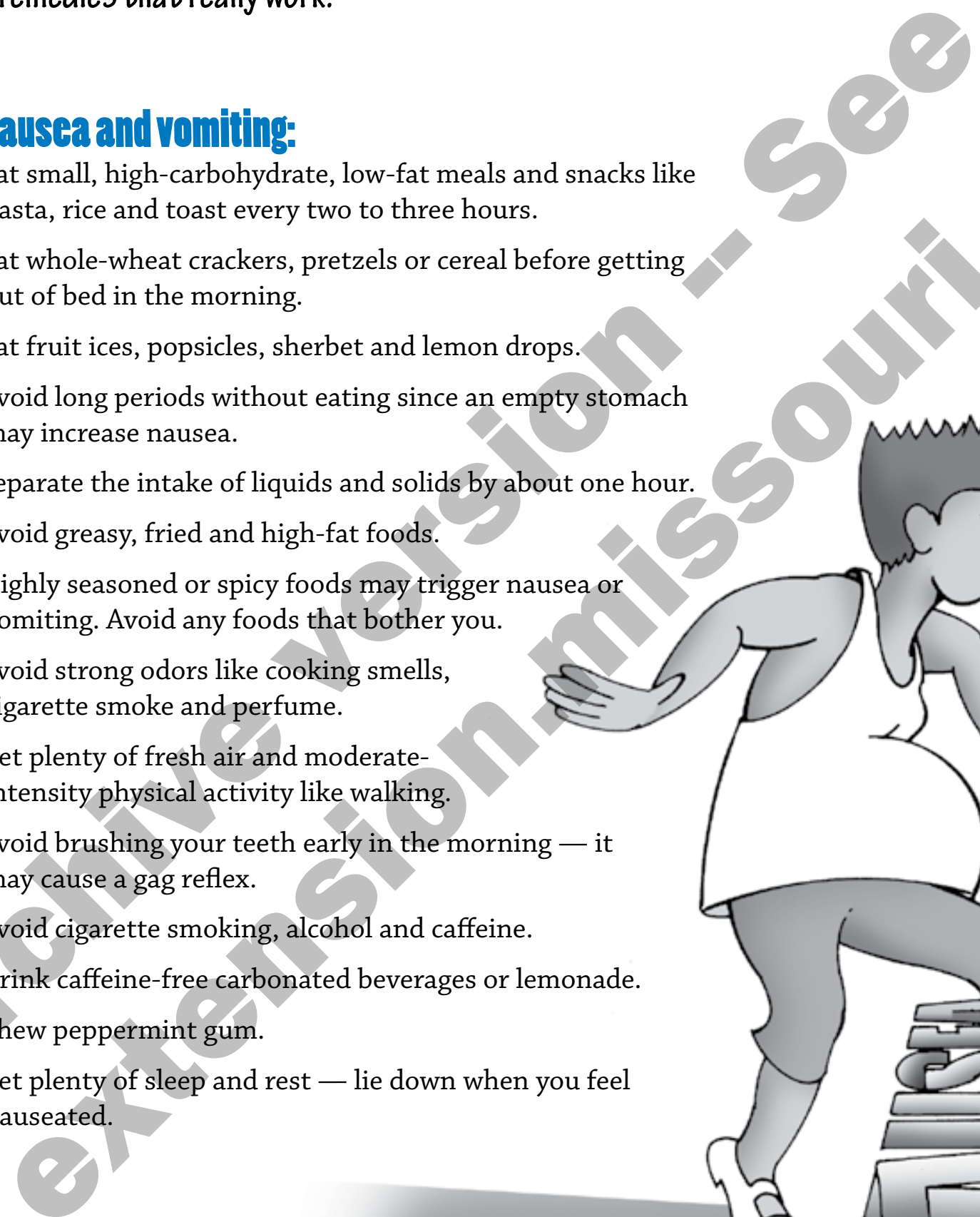


\section{Forhearthurn:}

- Eat small meals every two to three hours.

- Avoid lying down or bending over after eating.

- Limit foods that are highly seasoned, rich or fatty.

- Reduce the amount of fluids you drink with meals.

- Avoid tobacco and alcohol.

- Cut down on caffeinated drinks like coffee, tea and soda.

- Sleep with your head elevated.

- Avoid eating two to three hours before bedtime.

- Walk after you eat to encourage stomach juices to go down, not up.

- Wear loose, comfortable clothing.

- Antacids: Consult your health care provider before taking antacids. Some can keep your body from using certain vitamins and minerals.

\section{For constipation:}

- Eat more high-fiber foods like wholewheat bread, oatmeal, grits, wholewheat pasta, brown rice, bran and bran cereal, popcorn, dried beans and peas, fruits, vegetables (eat raw with skins when possible), dried fruit, and nuts and seeds.

- Eat regular meals and snacks.

- Drink at least 10 cups of fluid daily, like water, milk and fruit juice.

- Drink a warm beverage when you get up in the morning.

- Limit tea, coffee and colas with caffeine because they make you urinate more. This could cause you to become dehydrated.

- Exercise regularly.

- Do not take laxatives unless your health care provider prescribes them.

\section{For legcramps:}

- Avoid standing for long periods.

- Wear flat shoes.

- Exercise regularly.

- Be sure to eat the recommended amounts of high-calcium foods.

- Put your legs up during the day.

\section{For backache:}

- Make time for 150 minutes (two hours and 30 minutes) of moderateintensity aerobic physical activity spread throughout the week.

- Maintain good posture.

\section{CONSTIPATION LEG CRAMPS BACKACHE}

